\title{
CORRIGENDUM
}

\section{Thought-feeling discrimination in people with dementia: adaptation and preliminary validation of the first dementia-specific measure - CORRIGENDUM}

Joshua Stott, Tim Cadman, Henry Potts, Katrina Scior, Janina Brede, and Georgina Charlesworth

Key words: aging, cognitive behavioral therapy (CBT), anxiety, mood disorders, clinical assessment, corrigendum

DOI: https://doi.org/10.1017/S1041610219000322, Published by Cambridge University Press, 29 April 2019

The above article (Stott et al., 2019) published with the incorrect affiliation for Tim Cadman.

Tim Cadman's affiliation is as follows:

${ }^{1}$ Research Department of Clinical, Educational and Health Psychology, University College London, London, UK The original article has been corrected online to rectify this error.

\section{Reference}

Stott, J., Cadman, T., Potts, H., Scior, K., Brede, J. and Charlesworth, G. (2019). Thought-feeling discrimination in people with dementia: adaptation and preliminary validation of the first dementia-specific measure. International Psychogeriatrics, doi: 10 $.1017 /$ S1041610219000322. 